\title{
Impact of air pollution on severe acute exacerbation of COPD
}

This article was published in the following Dove Press journal:

International Journal of COPD

\author{
Miqdad Haider' \\ Muhammad Nabeel Shafqat ${ }^{2}$ \\ Mariam Zafar ${ }^{3}$ \\ 'Department of Internal Medicine, \\ Fatima Memorial Hospital, Fatima \\ Memorial College of Medicine \\ and Dentistry, Lahore, Pakistan; \\ ${ }^{2}$ Department of Medicine, University \\ of Medical Sciences "Serafin Ruiz \\ de Zarate" Villa Clara (UCMVC), \\ Villa Clara, Cuba; ${ }^{3}$ Department of \\ Medicine, Basic Health Unit, Nankana \\ Sahib, Pakistan
}

\section{Dear editor}

We would like to comment on the article "Harmful impact of air pollution on severe acute exacerbation of chronic obstructive pulmonary disease: particulate matter is hazardous" by Choi et al which was published recently. ${ }^{1}$ Keeping in view the current state of affairs of our planet, and knowing that industrialization is growing fast, this article is very important in highlighting some critical issues. This is what makes this article interesting and important at the same time.

COPD is a progressive lung disease characterized by persistent symptoms of the respiratory system and decreased airflow. The most common cause is tobacco smoking, while other contributing factors include genetics and air contamination. Long-term exposure to these irritants causes an inflammatory response in the lungs, resulting in narrowing of the small airways and breakdown of lung tissue. ${ }^{2}$

The solid and liquid particles suspended in air are called particulate matter (PM). Most of them are hazardous for human health. The exact mechanism by which these particles cause adverse effects is unknown, although various epidemiological studies have consistently demonstrated their toxicity. ${ }^{3}$

In this study, performed as a retrospective analysis, Choi et al have tried to find out the relation between various air pollutants and the incidence of severe acute exacerbations of COPD. This study, which examined various air pollutants causing hospitalization due to exacerbation of COPD during a period extending more than 2 years, concluded that air pollution increases the incidence of such events. PM was found to be the major contributor of air pollution in the studied area. There have been no previous similar studies in the particular region, as claimed by the authors.

Similar epidemiological studies have been conducted in other parts of the world, mostly on the general healthy population. Most of these studies support the association between PM and worsening of respiratory conditions. A review article by Anderson et al reached the conclusion that PM has a small but consistent and significant effect on human health. ${ }^{4}$ However, they agree that overall the small individual effects result in a large global public health burden. We would like to add here that an interesting study by Sacks et al tried to identify the groups susceptible to PM-related health effects; the study focused on age group, low-socioeconomic status, previous cardiovascular or respiratory diseases and genetics. ${ }^{5}$

In our opinion, similar studies must be conducted in other parts of the world, preferably multicenter studies, as results can be affected by factors like particular atmosphere, and racial and cultural differences of different regions of the world. Further studies are needed to make a comparison of PM-related health issues in developing and
Department of Internal Medicine, Fatima Memorial Hospital, Fatima Memorial College of Medicine and Dentistry, Shadman, Lahore, Pakistan Email miqdadI4@yahoo.com
International Journal of COPD 2018:13 2101-2103

2101 
developed countries. Future studies must be carried out for COPD exacerbations that do not require hospitalizations.

\section{Disclosure}

The authors report no conflicts of interest in this communication.

\section{References}

1. Choi J, Oh JY, Lee YS, et al. Harmful impact of air pollution on severe acute exacerbation of chronic obstructive pulmonary disease: particulate matter is hazardous. Int J Chron Obstruct Pulmon Dis. 2018;13: $1053-1059$.
2. Agustí A, Edwards LD, Rennard SI, et al; Evaluation of COPD Longitudinally to Identify Predictive Surrogate Endpoints (ECLIPSE) Investigators. Persistent systemic inflammation is associated with poor clinical outcomes in COPD: a novel phenotype. PLoS One. 2012;7(5): e37483.

3. Harrison RM, Yin J. Particulate matter in the atmosphere: which particle properties are important for its effects on health? Sci Total Environ. 2000;249(1-3):85-101.

4. Anderson JO, Thundiyil JG, Stolbach A. Clearing the air: a review of the effects of particulate matter air pollution on human health. $J$ Med Toxicol. 2012;8(2):166-175.

5. Sacks JD, Stanek LW, Luben TJ, et al. Particulate matter-induced health effects: who is susceptible? Environ Health Perspect. 2011;119(4): $446-454$ 


\section{Authors' reply \\ Juwhan Choi \\ Jee Youn Oh \\ Young Seok Lee \\ Gyu Young Hur \\ Kyung Hoon Min \\ Sung Yong Lee \\ Kyung Ho Kang \\ Jae Jeong Shim}

Division of Pulmonary, Allergy, and Critical Care Medicine, Department of Internal Medicine, Korea University Guro Hospital, Korea University College of Medicine, Seoul, Republic of Korea

Correspondence: Jae Jeong Shim

Division of Respiratory and Critical Care Medicine, Department of Internal Medicine, Korea University Guro Hospital, Korea University College of Medicine, 148 Gurodong-ro, Guro-gu, Seoul 08308, Republic of Korea

Tel +82226261029

Fax +8222626 II 66

Email jaejshim@kumc.or.kr

\section{Dear editor}

We would like to comment on the letter to the editor about our study. As was mentioned, most studies have admitted the adverse effects of particulate matter. However, studies on various conditions (age, sex, region, exposure history, outdoor activity and job) are lacking. Of course, a study of the nonhospitalized acute exacerbation of COPD group is also lacking and in need. However, the most important point here is that the fundamental mechanism of particulate matter has yet to be revealed. A recently published study by Ramanathan et al suggests that particulate matter may cause eosinophilic inflammation in a mouse model. ${ }^{1}$ Eosinophilic inflammation in the airway is likely to promote acute exacerbation of COPD, which we believe could explain the fundamental mechanism in our research. In addition, although our study is a retrospective and single-center study, Korea is one of the high-particulate matter countries, which is useful for analyzing the effect of particulate matter. And, we think that our study has a clinical advantage because it is a study of patients who were continuously followed up. We hope that a large-scale, prospective and multicenter study will be supported in the future.

\section{Disclosure}

The authors report no conflicts of interest in this communication.

\section{Reference}

1. Ramanathan M Jr, London NR Jr, Tharakan A, et al. Airborne particulate matter induces nonallergic eosinophilic sinonasal inflammation in mice. Am J Respir Cell Mol Biol. 2017;57(1):59-65.

Dove Medical Press encourages responsible, free and frank academic debate. The content of the International Journal of Chronic Obstructive Pulmonary Disease 'letters to the editor' section does not necessarily represent the views of Dove Medical Press, its officers, agents, employees, related entities or the International Journal of Chronic Obstructive Pulmonary Disease editors. While all reasonable steps have been taken to confirm the content of each letter, Dove Medical Press accepts no liability in respect of the content of any letter, nor is it responsible for the content and accuracy of any letter to the editor.

\section{Publish your work in this journal}

The International Journal of COPD is an international, peer-reviewed journal of therapeutics and pharmacology focusing on concise rapid reporting of clinical studies and reviews in COPD. Special focus is given to the pathophysiological processes underlying the disease, intervention programs, patient focused education, and self management protocols

\section{Dovepress}

This journal is indexed on PubMed Central, MedLine and CAS. The manuscript management system is completely online and includes a very quick and fair peer-review system, which is all easy to use. Visit http://www.dovepress.com/testimonials.php to read real quotes from published authors. 